\title{
COMPARAÇÃO ENTRE PREÇOS DE MEDICAMENTOS GENÉRICO, SIMILAR E REFERÊNCIA CONTENDO CIPROFLOXACINO $500 \mathrm{mg}$
}

\author{
Caroline Aparecida Lima ${ }^{1}$ \\ Rafael Viana Toledo ${ }^{2}$ \\ Willian Carvalho Nunes ${ }^{3}$ \\ Paulo Roxo Barja ${ }^{4}$
}

Resumo: Os Antimicrobianos são definidos como compostos naturais, sintéticos ou semi-sintéticos, cuja finalidade é prevenir ou tratar de doenças infecciosas causadas por micro-organismos patogênicos. Ele é comercializado sob prescrição médica e possui um medicamento de referência. O medicamento de referência é um produto inovador no mercado, que possui sua própria marca comercial. Ele tem qualidade, eficácia e segurança comprovados cientificamente através de testes que são registrados junto ao órgão federal ANVISA. O objetivo do estudo é demonstrar a diferença de preços existente entre os medicamentos analisados. $O$ valor dos medicamentos foi levantado através de pesquisa em drogarias, o que nos mostrou uma grande diferença de preço entre os medicamentos e quando comparado com o estudo que avaliou o princípio ativo, o medicamento com melhor custo benefício, são os similares

Palavras chave: Medicamentos de Referência; Medicamentos Genéricos; Medicamentos Similares; Cloridrato de Ciprofloxacino; Cipro.

\footnotetext{
${ }^{1}$ Mestrado em Bioengenharia/Univap, Brasil. E-mail: caroladelima@outlook.com.br.

${ }^{2}$ Mestrado em Bioengenharia/Univap, Brasil. E-mail: rafaeltoledo4@hotmail.com.

3 Mestrado em Bioengenharia/Univap, Brasil. E-mail: willian.nunes@yahoo.com.br

${ }^{4}$ Univap, Brasil. E-mail: barja@univap.br.
} 